\title{
Railway Train Ticket Generation through ATM Machine: A Business Application for Indian Railways
}

\author{
Amit Kumar Gupta \\ Department of Computer Engineering \\ National Institute of Technology \\ Kurukshetra, Haryana, India
}

\author{
Priyanka Ahlawat Mann \\ Assistant Professor \\ Department of Computer Engineering \\ National Institute of Technology, \\ Kurukshetra, India
}

\begin{abstract}
The reservation of railway tickets in India is done through by either of the two alternatives. The first one is that the individual himself goes to the counter opened by the Indian Railways and book the advance ticket i.e. reservation of ticket and other one methods is through online reservation. This methods are valid in time dependent, timing is response $8 \mathrm{AM}$ to $10 \mathrm{PM}$. Implementation of this proposed work we can provide general ticket and reservation ticket is available twenty four hours. Now here we are talking about an application which can be very useful for common people. We can use ATM for booking railway tickets besides withdrawing money.
\end{abstract}

\section{Keywords}

ATM Card, ATM, Net Banking, Banking industry, electronic commerce, Railway Reservation,

\section{INTRODUCTION}

Due to rapid population growth in the developing nations like India, Pakistan, Brazil \& some other African nations, there have been many problems in these nations. System maintenance and development of banking business leads to amount of work increase greatly. In order to discover and resolve the abnormal circumstance in time, and avoid producing greater adverse effects, it is important to apply one method of automatic monitoring. [1]

The Internet is a very strong technology and its applications have changed the many industries life. We have focusing on the banking industry; we examine the factors of information technology the Internet at three levels of analysis: the firm, the industry and external context of the industry. [2]

The IT platform construction plays a key role. The process restructuring of commercial banks is a significant transform for China's financial enterprises operating mode, this paper proposes a method for commercial bank's core business systems and Integrated Financial Enterprise (IFE) solution, and the commercial bank can accomplish the variance analysis to design core business systems and IT platforms. [3]

Banking is an area that has extended in many different ways in recent years, including telephone and online banking. Mbanking provides yet another channel for banking services, and in emerging markets, provides some possibility for becoming a primary channel. Mobile banking, a symbiosis of technology and financial services, is the hottest area of development in the banking sector and is expected to replace the debit/credit card system, online or net banking in future. [4]
From the perspective of Information Technology we can see that many of the problems could be solved effectively by efficient use of Information Technology. Here we are considering about the problems related to railways. Talking about the Indian Railways, one of the biggest organizations in the world, we can see that the effective use of technology could enhance its contribution to the development of nation. The reservation of railway tickets in India is done through by either of the two alternatives. The first one is that the individual himself goes to the counter opened by the Indian Railways and book the advance ticket i.e. reservation of ticket. This ticket can be of General Class or of Reservation (AC, 2AC, 3AC, sleeper). The second alternative provided by the Indian railways is to use Information Technology without standing in the long queues, and saves time too. In this process the ticket is booked online. Besides allowing online booking of rail ticket (s), it offers everything from railway map to railway ticket fare to timetable of train (s). A complete railway enquiry system is in place, with a click of the mouse allowing one to access / check the Indian Railways timetable, railway ticket availability and booking for any sector besides complete online train ticket reservations. Visitors to the website can use it not only for railway ticket reservation / booking but also to find out ticket availability and ticket confirmation or PNR status for any ticket on any train within the Indian Railways network. Also an individual can book tickets through the agents approved by Indian railways.

The problem exists when one tries to book a General Class ticket. To book a General ticket, one has to go to the railway station or book from the authorized agents. But this process becomes quite time consuming and people don't like to stand in queues because in every important junctions and platforms due to arrival of trains there is lots of crowds. Due to this reason, people are afraid of losing the train. So some people travel without ticket. Now this becomes a serious issue for the government as the revenues from the tickets will not come. So this problem needs to be solved. The problem can be solved effectively with the use of Information Technology.

\section{RELATED WORK/BACKGROUND}

An Automatic Teller Machine (ATM) is modeled. The ATM is online with the bank, that is, each transaction will be authorized by the bank on-demand and directly debited from the account's owner. The ATM works as follows. First, any customer will insert his/her own card in the ATM and then the ATM will ask for a Personal Identification Number (PIN). Once the correct PIN is given, the ATM will ask for the amount of money to be withdrawn. If the amount is available and if the owner has enough money on his credit then the said amount of money will 
be paid. Whether the amount of money is payable or not, i.e. the ATM has enough cash but could be the case the ATM has no change for that amount, will be also checked. Once the money is offered to the customer a countdown is started, i.e. the client has a determined amount of time to pick up the money. If this timeout is over, the money will be collected by the ATM and the transaction will be rolled back.

The static aspects of this model are described using a YAON diagram and I modify some module for Railway Ticket. In principle this is not necessarily so, but for working with a secure model the Controller class is working as a dispatcher of actions and it would have a log file with the trace of every transaction carried out with the ATM.

The class Card input has the methods for reading the code of the customer card and for ejecting the card from the ATM. The class Card input will interact through the Controller with the class Terminal, where the methods Req_PIN and Req_amount are defined, in order to get the PIN of the user and to verify if the given PIN is correct or not. The class Card will have the information of the cardholder, that is, the Card_number, PIN, and Account number. The Controller will interact with Bank using the information of the cardholder in order to get the authorization to pay (or not) the requested amount. The bank interface will send the request to the Accounting class, which belongs to the Bank package, in order to call the Debit method of the accounting class 3 . The Accounting class has the methods Rollback, Authorization and Debit which directly interact with the Accounts class. Rollback is for roll back a transaction (for the case anything is wrong) and should leave the account and the teller machine in the original state; Authorization will authorize or not an operation and Debit will extract the requested amount of money from the account in the case the operation is authorized. [8]

\section{PROPOSED WORK}

If we increase the railway reservation or increase the ways to book the tickets, then this problem of travelling without ticket can be solved. If we increase the horizons of applicability of ATM (Automated Teller Machine) then it would be effective. The use of ATM machine for the booking of railway tickets can be a step for the new technology for the railway booking.

First of all, we need to hold talks between various leading banks and railways ministry about the making of a common application. This common application will be seen in the screen of ATM machine and customers trying to book ticket can see it.
Till now we can use many applications like paying tax, online mobile recharge, money transfer etc.

Now here we are talking about an application which can be very useful for common people. We can use ATM for booking railway tickets besides withdrawing money. In this process first of all we insert our ATM card on the machine and insert our pin code in it. After inserting the ATM pin, we can perform according to our wish as indicated in the screen. As we enter ATM pin there would be options in screen: i) Banking \& ii) Railway Reservation or Railway Ticket. Now we can choose from the two options aforementioned. If the customer wants banking, he can click to the Banking option and proceed further. If the customer wants to book ticket, then one has to click the "ticket booking" option.

Now, as the customer clicks for the "book ticket" option, then there come two options a) General Ticket b) Reservation Ticket. If the customer presses the General ticket button then he can book a general class ticket. For this he has to insert the place (both the originating place of travel and destination place). Also he has to insert date of journey. In this way a customer can book a general Class ticket. In this process, the charges i.e. cost of ticket, bank service charge are to be decided by bank and railway ministry. This ticket can be cancelled anytime. However the date of cancellation must not exceed the date of travel. Or the customer can cancel the ticket at the place where the journey is to begin.

Now we talk about second option i.e. Reservation, this process is a bit complex. Here we have to enter the names of places (originating place and destination place). Also the date of travel. After this we will get a list about details of seats and their availability. Here one problem exists. That is the customer has to enter names of people through keyboard in the machine in case more than one people are travelling. If one can't insert the names then he can take the help from security guards. After completing all the procedures the customer has to reenter the pin code so as to transfer money. In this way reservation is done.

This ticket can also be cancelled anytime anywhere. If needed, the cancellation can be done through ATM. The usefulness of using ATM machine can be seen during to booking of "WAITING" Ticket. The ticket issued by ATM can be used for travelling in any trains as long as the ticket is of that train and the ticket is non AC. This is due to the fact that waiting AC ticket does not permit you to enter and travel in the $\mathrm{AC}$ compartment. 


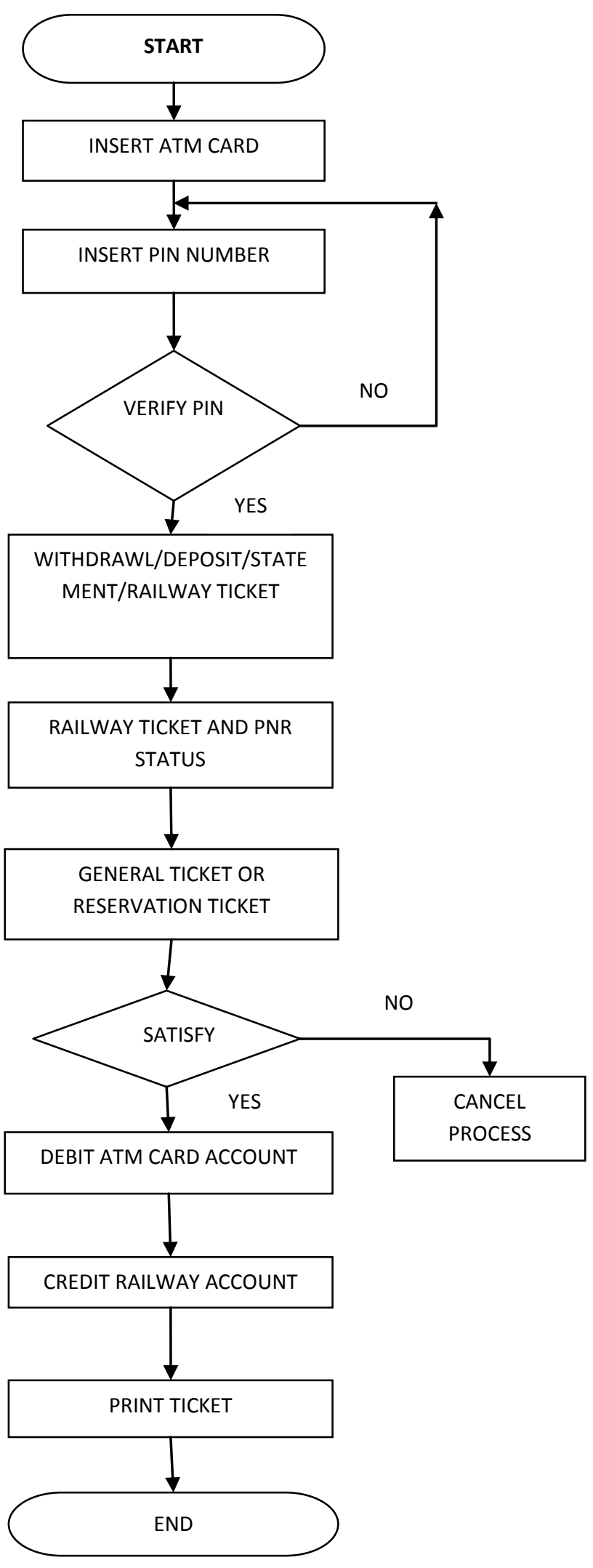

Here we are giving facility to the customer. If anyone wants to travel in sleeper class but he has done reservation, then there is a solution for him. If he wants to travel then he can go to a nearby ATM machine and book his ticket. Both Debit card and Credit card can be used to book his ticket. For this he has to insert his ATM pin code and select the Reservation option and select the "General Ticket With Reservation" option. After this he has to enter the train number and places of destination. After this he gets a sleeper class ticket to travel at day time. This facility is applicable for only day time travelling of trains and stations through which train travels during day. The time limit can be fixed from $6 \mathrm{am}$ in the morning to $10 \mathrm{pm}$ in the evening but it very $24 * 7$. A special case when the user does not have any money in his account then still he can book general ticket. This facility will be in accordance to the bank rules.

\section{ARCHITECTURE OF RAILWAY TICKET MODULE FOR ATM}

Figure 1 exhibits a flow chart diagram of ATM machine and working of online railway reservation module. In this phase we will describe the overall functionality of a ATM machine and the change in the architecture of ATM machine.

In fig 2, we are describing the actual architecture of ATM machine with online railway reservation module. In this architecture, we have used two servers: Bank Server or Bank Database and Railway reservation Server/Database. As shown in diagram, User/ATM card holder firstly inserts the ATM card in ATM machine. After inserting card machine will check the ATM account and balance in our account. After completion of this process, machine screen will show the different module. as per user requirements. User has to choose any module, if he need for money transaction so select the banking module, if he need to money transfer for one ATM account to another to ATM account, so choose money transfer module. Now, we are choosing the railway reservation module. In this module, we have to work on online railway reservation process. This module is give us the options for general ticket or Reservation Ticket. If passenger needs to book for general ticket so use general ticket generation and put destination place name (its means where the passenger wants to go). After putting name, system software automatic obtain the current date and generates a slip. When user confirms ticket, then process goes to in Debit/Credit Module. In this module, ATM account holder account debits and Credit the railway account. After this all process is complete, user get a printed slip. These slips are user railways ticket and allow user to travel anywhere in India within Indian railways. In this ticket we mention starting position and ending position and generate special random number. All transaction of money will be full secured and gives benefit to bank. Bank will charge some money in favor of providing this facility.

Fig2: Flow chart of proposed work 


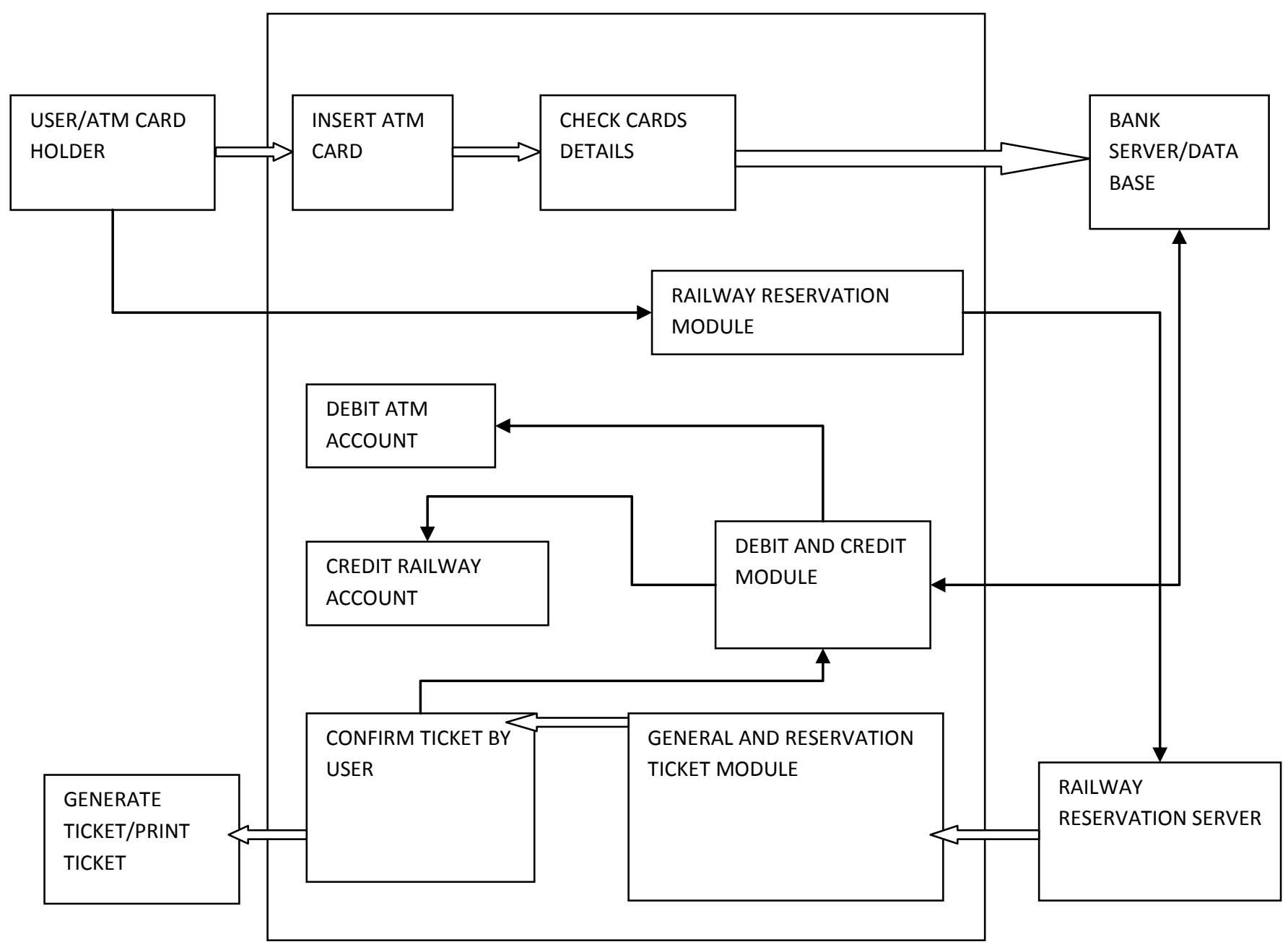

Fig 2: ATM Module for Railway Ticket Generation

\section{CONCLUSION}

A model for the integration of ATM machine and railway ticket booking is proposed. In this model we proposed a change in architecture of ATM machines by adding an option for railway ticket module. This module will work on the railway reservation server and bank server. This model provides user to book railway tickets (general/reservations) through ATM card. This feature will also help user to check the waiting list of railway reservation. The main motive is to give the common people a good and world class facility for railways travelling. Also to make people realize the fact travelling with ticket helps in the development of nation. Both passenger and railway reservation employee can save their time and effective utilization of time can be beneficial too. It's just that ATM machine will have one more load. Also it can reduce the queue in the railway ticket counter.

\section{REFERENCE}

[1] Jifang An and Jianhua Sun. 2010. An Application Of Banking Business Automatic Monitoring System Based On AIX Platform. Ninth International Symposium on Distributed Computing and Applications to Business, Engineering and Science.

[2] Shanthi Gopalakrishnan, J. Daniel Wischnevsky, and Fariborz Damanpour. 2003. A Multilevel Analysis of Factors Influencing the Adoption of Internet Banking. IEEE Transactions on Engineering Management, vol. 50,No.4

[3] Sheng Zhang, Gang Zhang, Qing Chang, Pingping Li, Yan Wang. A Solution of the Commercial Banks' System Architecture. The International Conference of Accounting, Business, Leadership and International Management, ICABL2009, P417-422. 
[4] Mahesh .K. Sharma , Dr. Ritvik Dube , Prospects of technological advancements in banking sector using Mobile Banking and position of India, 2009 International Association of Computer Science and Information Technology - Spring Conference

[5] Shusong $\mathrm{Ba}$, jian Lv. Reflections and Recommendations about Introducing Bank Core Business System. China's financial computer [J]. 2th, in 2006, P1-2.

[6] Central Bank of India, http://www.centralbankofindia.com

[7] State bank of India, http://www.statebankofindia.com.

[8] The Automatic Teller Machine, Available at http://projekte.fast.de/Projekte/forsoft/yaon/5_2Automatic_ Teller_Machine.html

[9] Stephen G. Kochan, Unix Shell Programming, 3rd ed., Beijing: China Railway Publishing House, 2004.

[10] Atkins, W "Will mobile get moving?" The Banker,4 November 2004, available on www.thebanker.com

[11] Claessens, S, Glaessner and Klingebiel et al (2003) "Electronic Finance: reshaping the financial landscape around the world" World Bank, available on http://www.worldbank.org/research/interest/confs/upcomin $\mathrm{g} /$ papersjuly11/E-finance.pdf.

[12] CPSS (2004) Survey of e-money and internet and mobile payments, BIS, available on www.bis.org

[13] Cracknell, D (2004) "E-Banking for the Poor: Panacea, Potential and Pitfalls", available via www.microsave.org

[14] Gray, V (2005) "The un-wired continent: Africa's mobile success story", available from http://www.itu.int/ITUD/ict/papers/index.html

[15] Millard, S \& V. Saporta (2005) "Central Bank and payment systems: Past, present, future", Background Paper to Bank of England Conference on Future of Payments May 2005

[16] Lyman, T, G Ivatury and S Staschen (2006) "The Use of Agents in Branchless Distribution for the Poor", CGAP Occasional Paper, forthcoming

[17] Gray, V (2005) "Evaluating the Cost of the handset and mobile telephony as a barrier to uptake", Presentation 6 December 2005, available from http://www.itu.int/ITUD/ict/papers/2005/ITU_Gray_FINA L_web.ppt 